\title{
Robotic-Assisted Spine Surgery: History, Efficacy, Cost, And Future Trends
}

This article was published in the following Dove Press journal:

Robotic Surgery: Research and Reviews

\author{
Marissa D'Souza (D) \\ Julian Gendreau' \\ Austin Feng ${ }^{2}$ \\ Lily $\mathrm{H} \mathrm{Kim}^{2}$ \\ Allen L Ho (iD) ${ }^{2}$ \\ Anand Veeravagu ${ }^{2}$
}

'Mercer University School of Medicine, Macon, GA, USA; '2Department of Neurosurgery, Stanford University School of Medicine, Stanford, CA, USA
Correspondence: Anand Veeravagu Department of Neurosurgery, Stanford University School of Medicine, 300 Pasteur Drive, R28I, Stanford, CA 94305, USA

Tel +1650 723-6469

Email anand.veeravagu@stanford.edu

\begin{abstract}
Robot-assisted spine surgery has recently emerged as a viable tool to enable less invasive and higher precision surgery. The first-ever spine robot, the SpineAssist (Mazor Robotics Ltd., Caesarea, Israel), gained FDA approval in 2004. With its ability to provide real-time intraoperative navigation and rigid stereotaxy, robotic-assisted surgery has the potential to increase accuracy while decreasing radiation exposure, complication rates, operative time, and recovery time. Currently, robotic assistance is mainly restricted to spinal fusion and instrumentation procedures, but recent studies have demonstrated its use in increasingly complex procedures such as spinal tumor resections and ablations, vertebroplasties, and deformity correction. However, robots do require high initial costs and training, and thus, require justification for their incorporation into common practice. In this review, we discuss the history of spinal robots along as well as currently available systems. We then examine the literature to evaluate accuracy, operative time, complications, radiation exposure, and costs - comparing robotic-assisted to traditional fluoroscopy-assisted freehand approaches. Finally, we consider future applications for robots in spine surgery.
\end{abstract}

Keywords: renaissance, robot-assisted surgery, $\mathrm{ROSA}^{\circledR}$, robotic spine surgery, SpineaAssist ${ }^{\circledR}$, Mazor $\mathrm{X}^{\circledR}$, computer assisted navigation, robotic navigation

\section{Introduction}

Over 4.83 million spinal operations are performed annually around the world, with 1.34 million operations taking place in the United States alone. ${ }^{1}$ In order to optimize and enhance surgeon performance, robot-assisted systems have been developed and deployed worldwide. ${ }^{2-5}$ In spine surgery, robotic technology has been utilized for spinal fusion and instrumentation procedures as it may aid with intraoperative navigation, trajectory determination, and screw implantation.

Widely used in a majority of spine operations, pedicle screws help stabilize the spine and facilitate fusion, but literature shows that complication rates associated with their implantation are not insignificant. ${ }^{6-12}$ Therefore, the desire for improved accuracy and decreased complication rates led to the development of computer navigation and roboticassisted surgery. ${ }^{6}$ Many initial reports of robotic-assisted spine surgery demonstrate that these methods offer screw placement accuracy superior to fluoroscopy-assisted free-hand screw placement. ${ }^{3,10,11,13-16}$ The use of robots may also reduce radiation exposure to both patients and providers. ${ }^{15}$ In this review, we discuss the history of surgical robot development as well as commercially available spinal robotic systems. We review accuracy, safety, and costs of robot-assisted procedures compared to traditional procedures. Finally, we discuss future applications and advances for robotic-assisted spine surgery. 


\section{History}

The concept of minimally invasive surgery (MIS) was born in 1987, the year of the first-ever laparoscopic cholecystectomy. After the widespread success of this operation, a large effort in the medical community was initiated in order to promote and expand upon this novel concept towards all surgical disciplines. The decreased invasiveness from MIS results in reduced incision sizes as well as decreased rates of post-operative infections, decreased length of patient hospital stays, and decreased duration of patient convalescence following surgery. ${ }^{17-19}$ Several studies have also demonstrated that minimally invasive procedures, such as those utilizing laparoscopy, lead to less pain, less blood loss, and less tissue trauma, while simultaneously allowing for better postoperative immune function and a quicker return to work for the patient. ${ }^{20-22}$ The obvious disadvantage to these new techniques is the learning curve required of the surgeon and surgical team. ${ }^{23}$

To further advance the practice and indications of MIS, both the medical community and private entrepreneurs began designing robots for the operating room. Compared to other fields (e.g. commercial industry and aviation), however, the medical field was much slower to adopt these robots. ${ }^{17}$ Despite this resistance, in 1985, the Programmable Universal Machine for Assembly 560 ([PUMA 560]; Unimation, Danbury, CT, USA) became the first-ever surgical robot used to perform a neurosurgical brain biopsy - with better reported precision than techniques of its time. ${ }^{24}$ Three years after its initial use, the PUMA 560 was utilized to perform a transurethral biopsy of the prostate. ${ }^{25}$ Amidst these successes, the National Air and Space Administration (NASA) began a strong research effort with the goals of creating a system that could perform remote surgery in space. The United States Army also joined this effort, as they envisioned using robotic surgery for treating wounded soldiers on the battlefield. Today, robotic surgery is widely utilized across many surgical subspecialties including gynecology, urology, and general surgery for minimally invasive procedures. With the help of increasingly advanced robots, surgeons in these fields have been able to greatly reduce the number of incisions made, demonstrating success in single-incision operations for colectomy, radical prostatectomy, cholecystectomy, myectomy, and many others. ${ }^{26-30}$ However, spine surgery only recently incorporated the robot into common practice with the first-ever widely utilized spine robot - the SpineAssist (Mazor Robotics Ltd., Caesarea, Israel) - gaining FDA approval as recently as $2004 .{ }^{31-33}$
Many technical errors of these spinal surgical robots were addressed in this initial developmental process. Early problems included incorrect synchronization of the intraoperative fluoroscopic images with the preoperative computed topography (CT) scan, excessive pressure on the guiding arm leading to altered accuracy of the arm, lengthy calculation times for screw insertions, software crashes, and improper attachment of the clamp to the spinous process. ${ }^{34,35}$

\section{Overview}

Robotic assistance in spinal surgery provides many benefits in the operating room for the patient, surgical staff, and surgeon, with many studies demonstrating that robotic surgeries have lower intraoperative complications than fluoroscopy-guided free-hand surgeries. ${ }^{13,36,37}$ From a technical perspective, blood vessels and nerve roots found in close proximity to hard bony surfaces create the potential for hemorrhage, sensory and motor loss if damaged intraoperatively in either surgical dissection or screw placement. ${ }^{35,38}$ Navigating intraoperatively is also challenging in patients with spinal and other skeletal deformities, osteoporosis, and tumors. ${ }^{7}$ Long and narrow paths to the spine are difficult to navigate by free-hand, and, thus, robotic navigation with collision avoidance greatly aids the surgeon in reaching these deep structures. Further, these robotic systems allow the surgeon to access three-dimensional visualizations of the patient's imaging and can also enable the surgical team to view the operation remotely via telesurgery. ${ }^{17,20}$

In addition to collision avoidance and intraoperative navigation, robots offer a number of other benefits including eliminating hand tremors, reducing surgeon fatigue, decreasing incision size, and providing up to 7 degrees of freedom while operating. ${ }^{3,33,39}$ Studies have reported that, because of reduced muscle retraction, there may be decreased postoperative pain for the patient. ${ }^{40}$ Because robots have also been found to help avoid damaging the proximal facet joint, they may also decrease rates of adjacent segment disease. ${ }^{41}$

Because bony landmarks used in the process of navigating to the surgical site often need to be visualized with fluoroscopy, patients, surgeons, and operating room staff are subject to large amounts of harmful radiation. This is especially important because spinal procedures can involve 10- to 12-fold higher amounts of radiation compared to non-spinal procedures. ${ }^{42}$ Because surgeons and surgical staff exposed to these high doses of radiation have 
increased levels of malignancy later in life, many surgeons elect to avoid minimally invasive approaches because they employ more fluoroscopy. A retrospective review of spine cases between 2004 and 2007 demonstrated that only $13.2 \%$ of spine cases were performed in a minimally invasive manner. $^{31,33,43,44}$ One significant aim of robotic research is thus to reduce radiation exposure to both patients and providers, and potentially increase the adoption of minimally invasive approaches.

Despite its intraoperative advantages, robotic surgery is still mostly confined to minor surgical procedures and has, to date, not seen wide adoption in neurosurgery or orthopedics compared to other surgical specialties. ${ }^{17,45}$ This may not be due to a lack of surgeon optimism regarding robotics but rather because of the complexity of the surgical operations performed in these fields. ${ }^{45}$ However, as robots are able to complete increasingly complex surgical tasks, the indications for robot-assisted surgery will continue to expand. For example, spinal tumor resections and ablations, revision procedures, vertebroplasties, and deformity correction are just a few of its emerging indications. ${ }^{46-48}$

Robotic surgery is not without its disadvantages. Current robots lack reliable tactile feedback and the use of these complex machines necessitates additional training and a larger surgical staff in the operating room. Additionally, robotic equipment is large and cumbersome with high initial costs often exceeding $\$ 1,000,000 .{ }^{17}$ Because of this, further studies are required to justify their extra labor and expense. $^{33}$

\section{Computer-Assisted Navigation (CAN)}

Both manual and robotic spine surgery have benefited from computer-assisted navigation $(\mathrm{CAN}) .{ }^{49}$ Widely used by many surgeons, image guidance is included in most currently available robotic platforms. ${ }^{9,50}$ Real-time image guidance, along with continuous computation and scan integration by the navigation system, allows the surgeon to visualize a comprehensive three-dimensional picture of the patient. Because of this, intraoperative CT scans paired with infrared and other optical guidance systems have significantly increased the surgeon's ability to accurately place screws. ${ }^{11}$ Navigation is now widely used in spinal procedures ranging from fusions to resections of intradural tumors to spinal deformity correction. ${ }^{39}$

There are many CAN options currently available for surgeons. These systems include the Airo Mobile Intraoperative computer tomography (CT)-based navigation system (Brainlab, Feldkirchen, Germany), the Stryker
Spinal Navigation system with the SpineMask Tracker and the SpineMap software (Stryker, Kalamazoo, Michigan), the Stealth Station Spine Surgery Imaging and Surgical Navigation system (Medtronic, Minneapolis, Minnesota), and the Ziehm Vision FD Vario 3-D system with NaviPort integration (Ziehm Imaging, Orlando, Florida). ${ }^{39}$ For surgeons operating with robot assistance, several CAN systems can be integrated with currently available robots. The Mazor $^{\circledR}$ and $\operatorname{ROSA}^{\circledR}$ robots can also have their native navigation software optimized for spinal operations.

\section{Currently Available Robots}

Medical robots generally fall into three categories: supervisory-controlled, telesurgical, and shared-control. Supervisorycontrolled robots allow the surgeon to plan the operation in its entirety pre-operatively; the robot then performs the operation under close supervision by the surgeon. Telesurgical robots allow the surgeon to directly control the robot and its instruments throughout the entire procedure from a remote location. Finally, most spinal surgery robots are shared-control robots that simultaneously allow both the surgeon and robot the ability to control instruments and motions. ${ }^{39,51}$

\section{Mazor: SpineAssist ${ }^{\circledR}$}

In 2004, the SpineAssist ${ }^{\circledR}$ (Mazor Robotics Ltd., Caesarea, Israel) was the first robot approved by the FDA for use in spinal surgery in the United States and remains one of the most widely used. ${ }^{52}$ The SpineAssist is a shared-control robot that offers navigation superior to traditional intraoperative CAN. Traditional CAN requires the surgeon to follow pre-planned trajectories manually, which often requires significant hand-eye coordination. The SpineAssist can automatically position its arm along a pre-determined trajectory, reducing the amount of complex movement required by the surgeon. ${ }^{53,54}$ All drilling is then performed by the surgeon. ${ }^{55}$ In addition to providing optimal positioning for screw insertion, the SpineAssist system offers 6 degrees of freedom of motion for surgical instrumentation and has the ability to include multiple different arms - each of which is able to accommodate drill guide sleeves. ${ }^{4,53}$

Performing spinal fusion operations using the SpineAssist typically requires five main steps. ${ }^{3}$ First, after obtaining 1-mm preoperative CT scans of the spinal levels of interest, the surgeon creates the trajectory for the screws within the native robot software package. Using these trajectories and its proprietary anatomical algorithms, the SpineAssist calculates the optimal screw size and anatomic alignment coordinates. $^{3,56}$ This trajectory is stored within the 
robot itself. If preoperative CT scans are unable to be obtained preoperatively or if preplanned screw trajectories require modification, the surgeon can create or update the screw trajectory intraoperatively. Second, after the patient is placed in a prone position in the operating room, a mounting frame is attached to the patient's spine for image registration purposes. ${ }^{3}$ Depending on the specific goals of the surgery and whether the operation is open or percutaneous, there are several different mounting options to help optimize the operational setup. Most commonly, the surgeon attaches the platform to the patient's spinous processes using one Kirschner-wire (K-wire) before using two additional $\mathrm{K}$-wires to secure the platform to the patient bilaterally (Figure 1). ${ }^{57}$ For minimally invasive procedures, rather than attaching the frame to the spinous processes themselves, the robot is attached to a frame held up by percutaneously placed guide wires. ${ }^{55}$ Third, once the frame is secured and the image registration fiducials are placed, six fluoroscopic images are captured, synchronized with the pre-operative images, and stored on the SpineAssist. ${ }^{3}$ An added benefit of the SpineAssist is this ability to pair images from different imaging modalities, allowing the user to sync preoperative CT scans with intraoperative fluoroscopy if desired. Using these images and its proprietary 3D marker, the robot verifies platform placement, reconstructs the operational field, and independently registers each vertebrae. ${ }^{56}$ Fourth, the robot is attached to the mounting frame, ${ }^{3}$ and it automatically aligns its arm according to the planned trajectory. K-wires are then inserted, and correct placement is confirmed. Once trajectories are verified, a cannulated dilator is placed through the surgical arm followed by a drill guide and guidewire. ${ }^{56}$

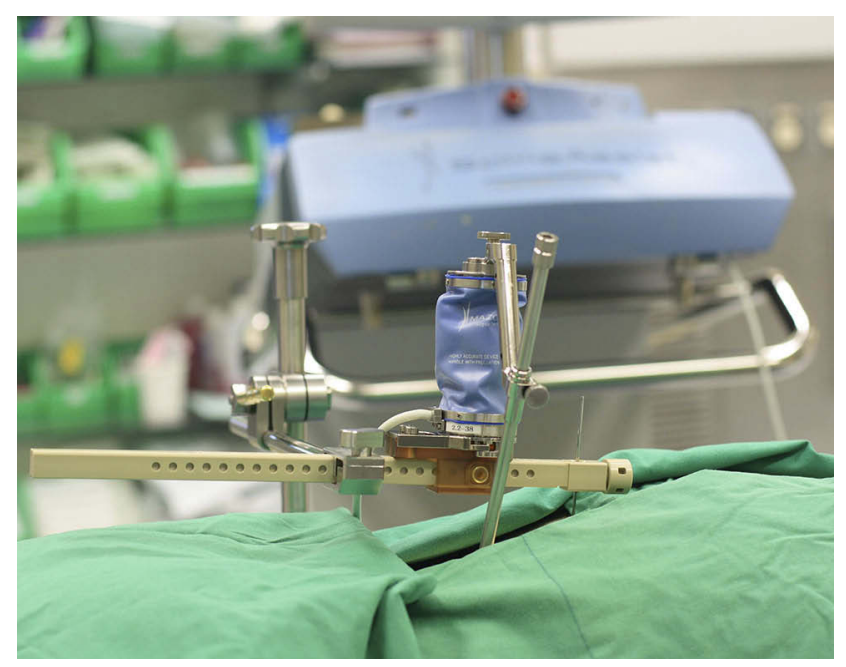

Figure I Following the pre-operative CT, the SpineAssist robotic platform is attached to the spine for final image registration.
Finally, screws are placed using the guide wires. The robot hardware is then disassembled and removed from over the patient. ${ }^{3,56}$ This workflow is displayed in Figure 2.

Because of the wide utilization of the SpineAssist in spine surgery, many studies detail its main issues. ${ }^{6,55}$ In one study, robotic placement of pedicle screws was aborted due to difficulties involving tool skiving and trajectory completion. ${ }^{6}$ Separately, cannulas positioned at the screw entrance point can slide, leading to screw positioning that is more lateral than desired. ${ }^{55}$ Ringel et al used a percutaneous approach with one K-wire attached to the spinous process and two Steinmann pins attached to the posterior superior iliac spines; they noted instability in the K-wire leading to malpositioned drill sleeves and skidding of the drill cannula. $^{55}$ Finally, even though there can be decreased intraoperative radiation exposure, the radiation of the preoperative CT scan is still necessary. ${ }^{6}$

\section{Mazor: Renaissance ${ }^{\circledR}$}

The Renaissance ${ }^{\circledR}$ is the Mazor's second-generation spine robot, replacing the SpineAssist in 2011. While both robots are similar in terms of their patient-mounted platforms and mechanical arms, the Renaissance includes both software and hardware improvements such as upgraded image recognition algorithms and the ability for the surgeon to flatten the bone around screw entry points before drilling. This process assists in preventing the skidding of the guiding cannula on a sloped anatomy. ${ }^{58}$ Both the SpineAssist and Renaissance have been found to result in accuracy rates ranging from $85 \%$ to $100 \% .^{53,54,59}$ The Renaissance has faced similar problems to its first-generation counterpart, the most significant of which is screw misplacement secondary to skiving. ${ }^{6}$

\section{Mazor: Mazor $\mathrm{X}^{\circledR}$}

Introduced at the North American Spine Society (NASS) Annual Meeting in 2016, the Mazor $\mathrm{X}^{\circledR}$ is the most recent release by Mazor. Similar to previous models, the Mazor $\mathrm{X}$ comprises a workstation and mechanical surgical arm. Unlike previous models, however, the robotic arm includes an integrated linear optic camera that allows the robot to perform a volumetric assessment of the work environment in order to self-detect its location and provide collision avoidance intraoperatively. To do this, the camera performs an intraoperative 3D scan following the placement of a reference pin in the patient's spine. Further, the Mazor $\mathrm{X}$ allows each vertebral body to be registered independently and hence has its own accuracy. Another benefit the 
1-mm Preoperative CT Imaging, Trajectory Development and Calculation of Optimal Screw Size and Alignment

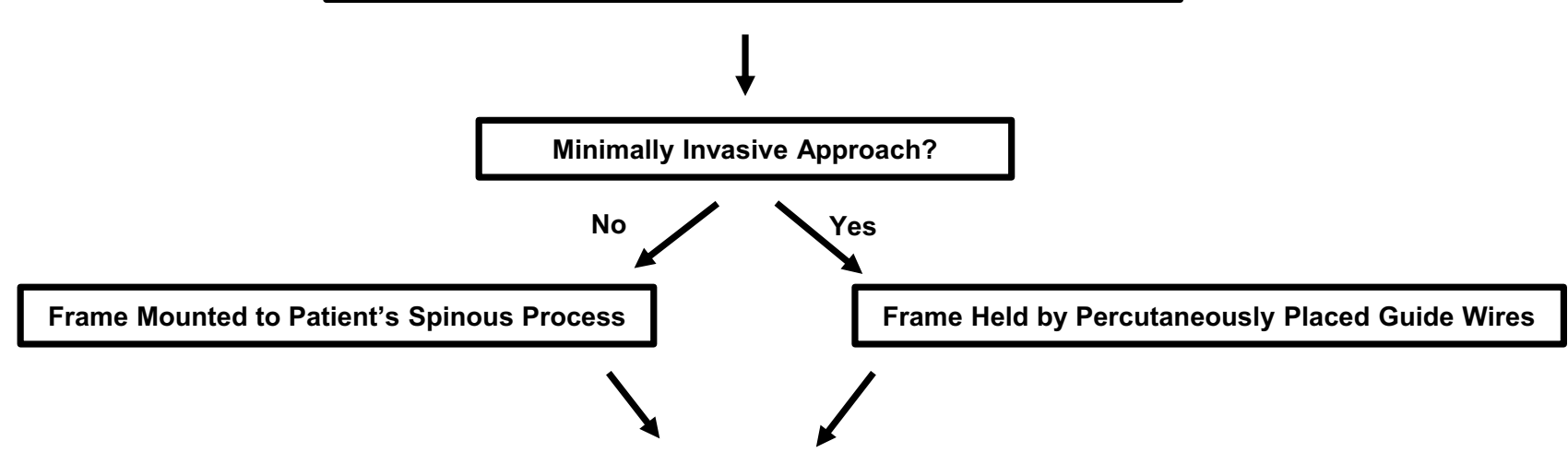

Fluoroscopic Imaging Obtained and Synchronization with Preoperative Imaging

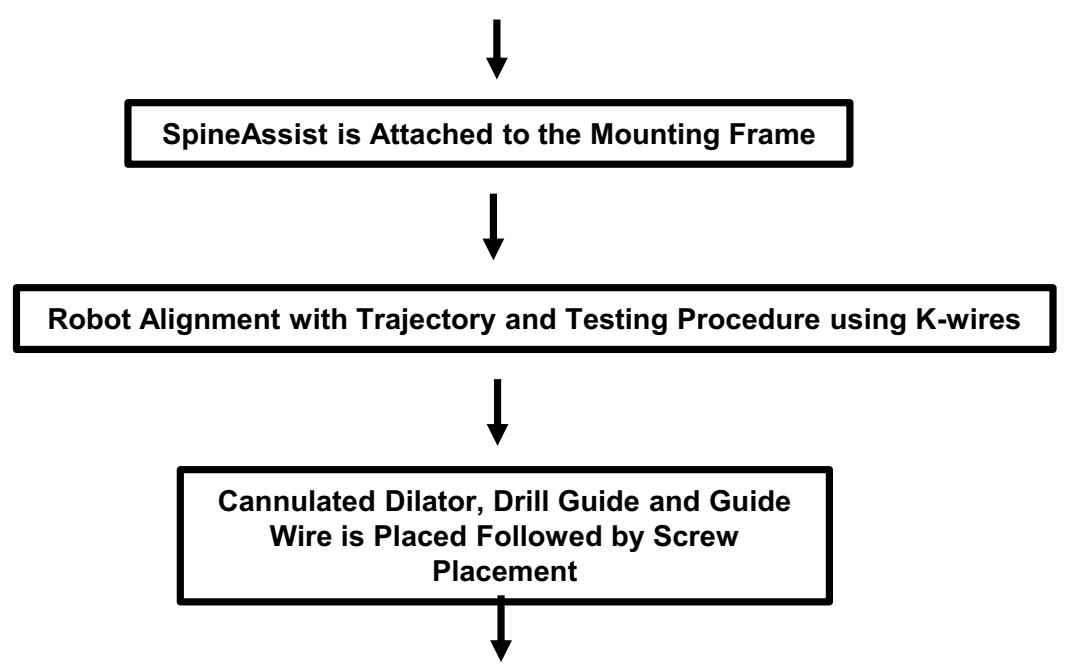

Robot Disassembly

Figure 2 SpineAssist workflow of preoperative planning, frame mounting, robot attachment, screw placement and disassembly.

robot offers is its serial, rather than parallel, robotic arm; this increases the work capacity of the system and leads to an increased range of motion and reduced reliance on surgical tools. ${ }^{60}$

\section{$\operatorname{ROSA}^{\circledR}$ Spine}

The initial ROSA ${ }^{\circledR}$ BRAIN robot (Zimmer Biomet Robotics, Montpellier, France) was designed for cranial operations and was cleared by the FDA in $2012 .{ }^{39}$ Created based on the brain version, the ROSA ${ }^{\circledR}$ SPINE was recently approved by the FDA in 2016. Similar to the Mazor X, the free-standing ROSA utilizes a robotic arm and navigation camera - each mounted to their own floorfixable mobile bases - in order to optimize and guide pedicle entry points and trajectories. ${ }^{61}$ The stereoscopic camera can be used for navigation, potentially fixing some of the problems previously associated with the SpineAssist. While the SpineAssist could not properly account for movements by the patient intraoperatively, the Mazor X and ROSA utilize their cameras to track patient movements and accordingly readjust the robot position in real time. Like the Mazor $\mathrm{X}$, this newly released robot has not yet been widely validated in academic literature for use in spinal pedicle instrumentation due to lack of comprehensive data. ${ }^{39}$

Similar to the robots previously discussed, the ROSA initially requires a preoperative $\mathrm{CT}$ scan for image acquisition. In the operating room, the O-arm ${ }^{\circledR}$ device and ROSA are put into place ${ }^{57}$ Using a percutaneous reference pin placed in the iliac wing, a "fiducial box" held by the 
robotic arm, and images from the O-arm, the ROSA performs automatic image registration and produces a $3 \mathrm{D}$ reconstruction. The surgeon then merges the preoperative and intraoperative scans in order to plan the $3 \mathrm{D}$ trajectory. $^{19}$

Next, the robotic arm aligns itself with the preplanned trajectory. A guide-tube needle is then placed into the posterior part of the vertebral body, through which a guidewire is threaded. Following placement of the wire, the needle is removed. Using the guidewire, the surgeon then threads the cannulated dilator through the pedicle and inserts the screws in the vertebral bodies - all under realtime navigation guidance. Rods are placed and a final CT scan is used to verify correct positioning. ${ }^{19}$ Finally, the surgical arm is removed, and the wounds are closed.

Limitations of the ROSA include those common to most robots: its steep learning curve, need for experienced surgeons, inability to create preplanned screw trajectories, and lengthy time needed to position the patient and set-up the robot. Further, the reference array must also not be touched, as the robot would register this as a movement by the patient, resulting in improper screw placement. While the real-time guidance feature is a major advantage of the ROSA, this guidance is based on 3D mapping of the patient performed at the beginning of the operation. Therefore, if the patient moves significantly during the procedure, the robot will no longer be accurate. ${ }^{19,62}$

\section{Intuitive Surgical: Da Vinci Surgical System $^{\circledR}$}

The da Vinci Surgical System ${ }^{\circledR}$ (Figure 3) was developed by Intuitive Surgical (Sunnyvale, California) and was FDA-approved in 2000 for general laparoscopic procedures. $^{39,63,64}$ The da Vinci utilizes the telesurgical model by which the surgeon operates from a remote telesurgical booth equipped with $3 \mathrm{D}$ vision screens, thereby allowing the robot to serve as an extension of the surgeon's arm. ${ }^{17}$ The da Vinci has been widely studied, yielding results that show superior visualization and magnification compared to traditional laparoscopy. ${ }^{38,65-67}$ Other benefits include control grips for the surgeon, 7 degrees of freedom, tremor filtering, high definition video, and improved ergonomics. ${ }^{31,39,68}$

The da Vinci has a relatively larger setup compared to other robots used in spinal surgery. The robot's components comprise a booth where the surgeon sits and operates, an instrument and camera cart, a vision cart to which

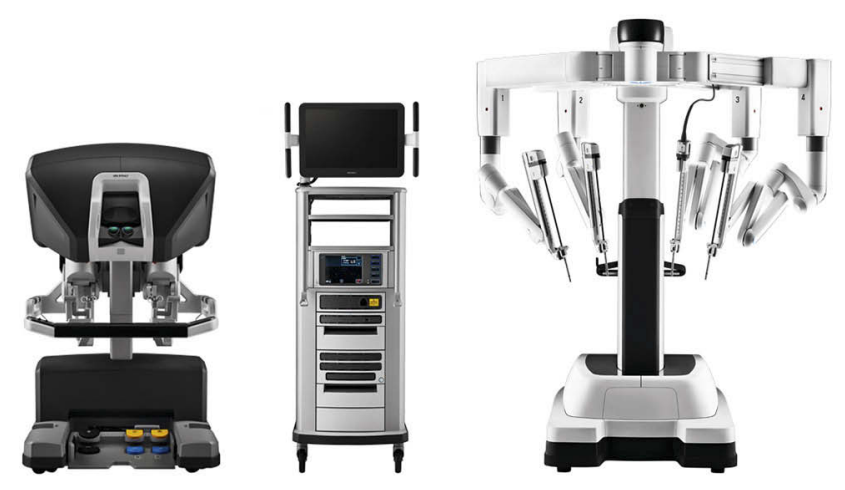

Figure 3 The da Vinci Surgical System ${ }^{\circledR}$ (Intuitive Surgical, Sunnyvale, California) robot. Image courtesy of Intuitive Surgical Inc. da Vinci Si System with single-site instrumentation. Surgeon console, surgeon, da Vinci ${ }^{\circledR}$ Si patient cart with SingleSite ${ }^{\mathrm{TM}}$ instruments. Available from: https://www.intuitivesurgical.com/company/ media/images/singlesite.php. Accessed September 22, 2019. Copyright (C) 2019 Intuitive Surgical, Inc. ${ }^{64}$

attachments for light sources for the procedure are mounted, and multiple operating arms. ${ }^{68}$ The dual set of cameras provides a 3D video for the surgeon. Additionally, there is a separate remote booth with override potential, making the system ideal for trainee education. ${ }^{39}$

In spinal surgery, the da Vinci robot has been utilized for numerous procedures including anterior lumbar interbody fusions (ALIF), resection of thoracolumbar neurofibromas, resection of paraspinal schwannomas, and transoral odontoidectomies. ${ }^{48,66,67,69,70}$ Originally, laparoscopic ALIF showed no benefit compared to the traditional free-hand technique in terms of reducing patient blood loss, length of stay, complications and operating times. Therefore, laparoscopy was largely abandoned for this procedure in its entirety. ${ }^{71-74}$ However, the advanced capabilities of the newer generations of the da Vinci robot make completing ALIF laparoscopically both possible and efficient. Case series have shown successful dissection, exposure, and interbody placement without any vessel or ureteral complications. ${ }^{69}$

\section{Globus Medical: Excelsius GPS ${ }^{\circledR}$}

Cleared by the FDA in 2017, the Excelsius GPS $^{\circledR}$ (Globus Medical, Inc., Audubon, Pennsylvania) has great potential in the field of spine surgery. ${ }^{31}$ It features real-time intraoperative imaging, automatic compensation for patient movement, and direct screw insertion through a rigid external arm - obviating the need for $\mathrm{K}$-wires or clamps. Feedback is provided instantly via the robot's monitor if the drill skives or the reference frame moves. ${ }^{31,75}$ While the robot is similar to the Mazor and ROSA, there is little research pertaining to 
its accuracy in the operating room due to its very recent FDA clearance.

\section{Learning Curve And Training}

Accuracy of screw placement has been found to be positively correlated with surgeon experience and familiarization with the robot. ${ }^{76,77} \mathrm{Hu}$ and Lieberman followed a single surgeon from 2010 to 2012 and analyzed outcomes of 150 patients undergoing posterior spinal procedures with pedicle screws. ${ }^{76}$ The rate of successfully placed screws significantly increased with experience, increasing from $82 \%$ to $93 \%$ for the first and last group, respectively. Further, the rate of screws converted to manual placement decreased with increasing experience. The overall malposition rate of the screws was $0.7 \%$ and was found to not be correlated with the surgeon's experience. ${ }^{76}$

In a similar study aimed to determine the learning curve associated with CAN, the learning curve sharply dropped after 6 months and plateaued at 12 months for both a spine surgeon with 10 years of experience and a spine surgeon with 20 years of experience. After 12 months, the lumbar pedicle screw cortical perforation rate decreased by $3.9 \%(\mathrm{P}=0.006)$ for one of the surgeons and by 5.6\% $(\mathrm{P}<0.001)$ for the other surgeon. Operative time was significantly reduced $(\mathrm{P}<0.001)$ by 20.9 mins and 40.3 mins for the CAN groups of surgeon $\mathrm{A}$ and $\mathrm{B}$, respectively, as well. ${ }^{77}$ On a separate note, it has also been demonstrated that skilled control of the robot can lead to the decreased radiation exposure time. Specifically, Kim et al found that total fluoroscopy time decreased by $30 \%$ after the first eight cases. ${ }^{78}$ For this reason, they suggested that at least 10 cases are necessary to gain the experience needed to minimize radiation exposure time. ${ }^{78}$

Kaul et al concluded that da Vinci assistance decreased the learning curve for standardized tasks as well as actual laparoscopic operations. ${ }^{79}$ Surprisingly, they also found that prior surgical experience, whether open or laparoscopic, was not required to develop robotic competence. Because of this, they suggested that the da Vinci could not only be utilized to mentor trainees in residency programs but also could serve as a continued skills assessment tool throughout their training. ${ }^{79}$ This study brings up an interesting point in that robotic technology has an added benefit of being able to record and track user data; these data can be used to objectively measure surgical dexterity and other manual competencies.

\section{Clinical Outcomes And Accuracy}

Many studies have demonstrated that robotic-assisted screw placement results in accuracy greater or comparable to that of conventional or CAN pedicle screw placement. $3,6,14,16,55,61,80,81$ Only one published randomized controlled trial reported decreased accuracy with a Mazor robot. ${ }^{55,59}$ To find these studies, a literature review was performed using PubMed and combinations of the following search terms: "robot", "surgery", "spine", "screw placement", "accuracy", "radiation", and "operative time". Only studies published in English in the last ten years were included in this review. The accuracy outcomes of these studies are summarized in Table 1. In 2013, Hu et al found that out of 960 screws implanted using the robot, $98.9 \%$ were successfully implanted; the remaining $1.1 \%$ were malpositioned secondary to skiving of the drill bit or trocar off the facet. ${ }^{6}$ Screws were manually implanted in $10.1 \%$ of the cases, and $1.4 \%$ screws were not placed because of intraoperative determination that the screws were not needed for construct stability. Additionally, certain patient factors (including high body mass index, severe deformity, and extremely poor bone quality), and technical factors (including difficulties with platform mounting, with registration secondary to previously placed loosened hardware, and the device itself) prevented the robot from being used in the operation. ${ }^{6}$

Le et al conducted a retrospective, matched-cohort study, comparing accuracy of screw placement, radiation exposure, operative time, inpatient length of stay days, and complications of 58 patients undergoing robot-assisted (RG) versus fluoroscopy-assisted (FG) cortical bone trajectory screw placement in lumbar spinal surgery. ${ }^{14}$ They found the robot-assisted procedures to be more accurate and with higher fusion rates than the fluoroscopy-assisted procedures (95.3\% [RG] vs $86.9 \%$ [FG]; $\mathrm{P}=0.038)$. In terms of radiation, although the cumulative radiation time was greater in the robotic group (142.8 s [RG] vs $77.5 \mathrm{~s}$ $[\mathrm{FG}] ; \mathrm{P}=0.346$ ), the dose of exposure to the doctors was significantly reduced in the robotic arm $(32.7 \mu \mathrm{Sv}[\mathrm{RG}]$ vs $75.7 \mu \mathrm{Sv}[\mathrm{FG}] ; \mathrm{P}=0.003)$. Operative time was slightly increased in the robotic arm as well (199.1 mins [RG] vs 119.5 mins $[\mathrm{FH}] ; \mathrm{P}=0.000)$. No differences were noted in postoperative hospital length of stay or surgical infection rates between the two groups. ${ }^{14}$

Of 2,067 screws implanted between two centers in Germany, Keric et al found $96.9 \%$ of the screws to be placed accurately in "acceptable or good" position. ${ }^{80}$ Similarly, another study retrospectively reviewed data from both robotically guided spinal implants and unguided free-hand procedures across multiple centers 


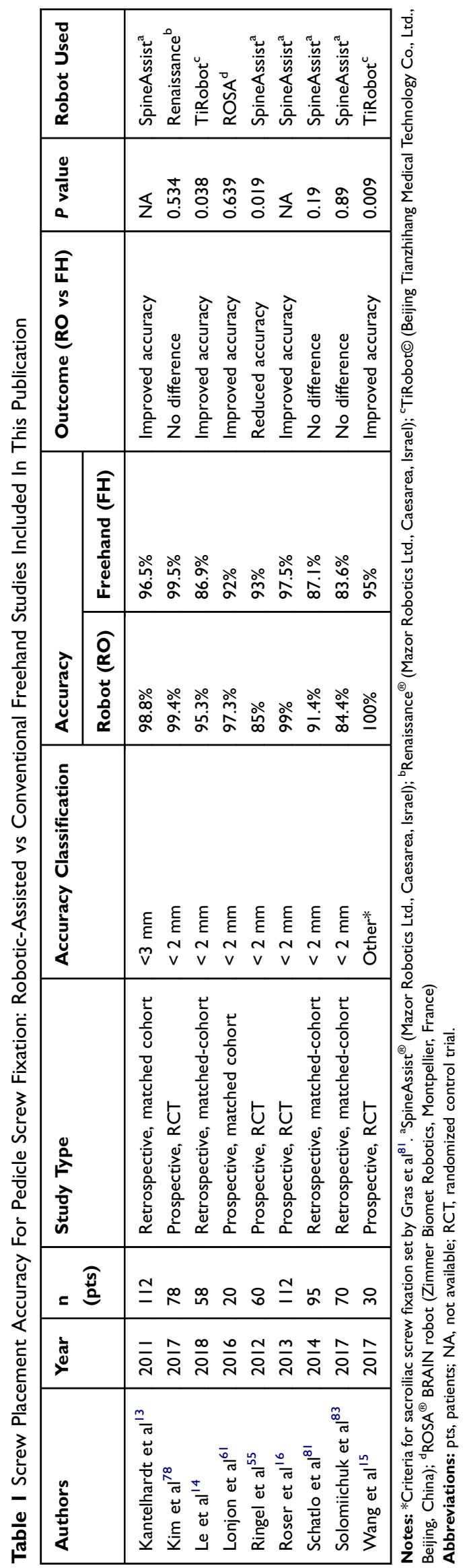

in Atlanta, Ohio, Israel, and Germany. ${ }^{3}$ Resulting in a 98.3\% placement accuracy rate and fewer neurologic complications, the SpineAssist offered enhanced performance over free-hand surgeries. The average error across this study was less than $2 \mathrm{~mm}$, and no permanent nerve damage occurred in any of the patients. Further, $49 \%$ of these operations were performed percutaneously, demonstrating how robotic assistance can enable minimally invasive approaches. ${ }^{3}$

Recently in February 2018, Yu et al published a meta-analysis comparing robotic-assisted (RA) and freehand $(\mathrm{FH})$ conventional approaches for pedicle screw fixation. ${ }^{2}$ Including data from 750 spine patients, they found no significant differences between RA and FH techniques in screw placement accuracy (95.5\% [RA] vs $92.9 \%[\mathrm{FH}] ; P=0.51)$, complication rate $(1.33 \%[\mathrm{RA}]$ vs $3.45 \%[\mathrm{FH}] ; P=0.18)$, major complications $(0.89 \%$ [RA] vs $2.16 \%[\mathrm{FH}] ; P=0.39$ ), and radiation exposure time (weighted mean difference $=8.49 ; \quad P=0.49$ ). However, while the authors did find a significant increase in operative time with the RA procedures (weighted mean difference $=39.63 ; P=0.02$ ), they noted a significant decrease in radiation exposure time with percutaneous or minimally invasive robot-assisted screw fixation compared to $\mathrm{FH}$ (weighted mean difference $=-33.10 ; P=0.00)$. This meta-analysis had a smaller sample size with only 750 patients, and while it demonstrated increases in screw placement accuracy and lower rates of complications with robotic-assisted approaches, these increases were not statistically significant. ${ }^{2}$ When considering complications of pedicle screw fixation with these two techniques, it is interesting to note that $\mathrm{Yu}$ et al found that $100 \%$ of the complications in the robotic-assisted group were a result of infection, while $75 \%$ of the complications in the freehand group were related to the placement of the pedicle screw. The increased infection rates could potentially be the result of longer operating times for the robotic group. ${ }^{2}$

Sacroiliac (SI) screw placement can be very demanding. High rates of malpositioned screws - ranging from $2 \%$ to $15 \%$ - for this procedure can be attributed to complex pelvic anatomy. ${ }^{15}$ In a study of 30 patients, Wang et al compared robot-assisted to conventional freehand SI screw implantation. ${ }^{15}$ They found that robot-assistance led to significantly higher rates of screw placement accuracy, with the robot-assisted group demonstrating an accuracy of $100 \%$ (vs $95 \%$ 
[FH]; $P=0.009$ ), using accuracy criteria previously set by Gras et $\mathrm{al}^{82}$. Additionally, fluoroscopy time was significantly reduced in the robot-assisted group $(6.0 \mathrm{~s}$ [RO] vs $36.0 \mathrm{~s}[\mathrm{FH}] ; P<0.001)$. Time for guidewire insertion and number of guidewire attempts were also shorter in the robotic arm. There were no differences found in instrumented iliosacral levels or operative time after pelvic reduction between the two groups. ${ }^{15}$

More and more, robotic systems have successfully been utilized for increasingly complex spinal surgeries. In a retrospective matched cohort study in Switzerland of 70 patients with thoracolumbar metastatic spinal disease, the SpineAssist was used for $47 \%$ of implanted screws based on robot availability. ${ }^{83}$ The authors found comparable accuracy, radiation time, and postoperative infection rates between the robotic and conventional fluoroscopic guided free-hand methods. Clinically acceptable trajectories (Grade A or B) were observed in a higher proportion of screws using the robotic technique (84.4\%) compared to those placed using the conventional technique (83.6\%), but this difference was not significant. Similarly, the misplacement rate was $15.6 \%$ in the robotic group compared to $16.4 \%$ in the conventional group, but this difference was not significant either. ${ }^{83}$

Dreval et al demonstrated that robots can also successfully be utilized for transcutaneous transpedicular interventions, biopsies from hard-to-reach regions of vertebral bodies, and vertebroplasties for the treatment of hemangiomas and vertebral body fractures with high accuracy, safety, and efficiency. ${ }^{52}$ In vertebroplasties, the SpineAssist allows the direct introduction of filling material into the hemangioma and within the fracture region. ${ }^{52}$

To treat an especially aggressive and hard-to-access sacral S1-S2 hemangioma contraindicated to the usual treatments, Kaoudi et al utilized robot-assisted radiofrequency (RF) ablation. ${ }^{84}$ Not only was this the first reported instance of RF ablation used in the treatment of sacral hemangiomas, but also it was the first observation of robot-assisted RF ablation in spine surgery. The ROSA Spine was used to place the RF ablation probe into the central part of the hemangioma via a transiliac-transpedicular sacral approach. ${ }^{84}$ Separately, many publications have also validated the use of robotic guidance for the placement of S2 alar-iliac screws. ${ }^{85-88}$

The operative times and radiation exposure times from the studies highlighted in this publication are summarized in Tables 2 and 3, respectively.

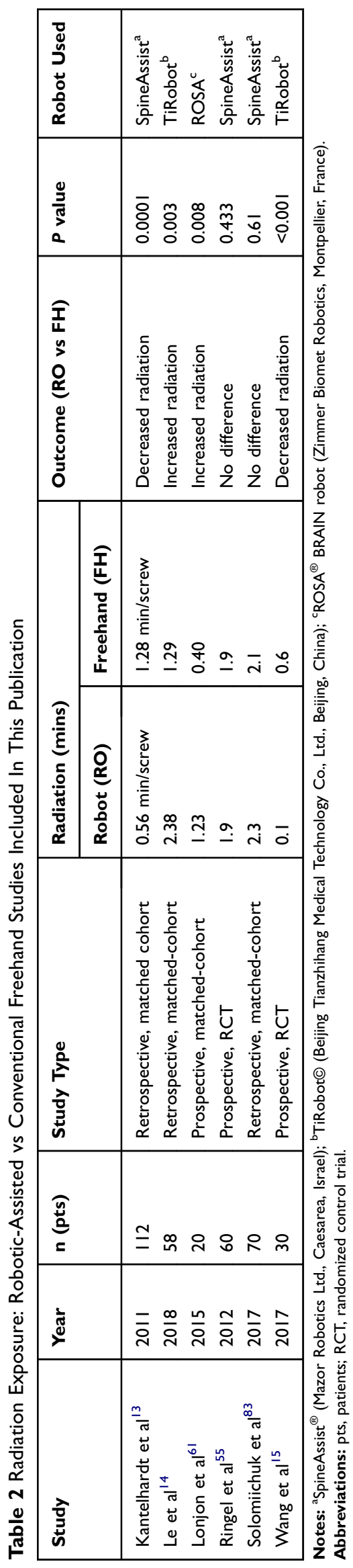




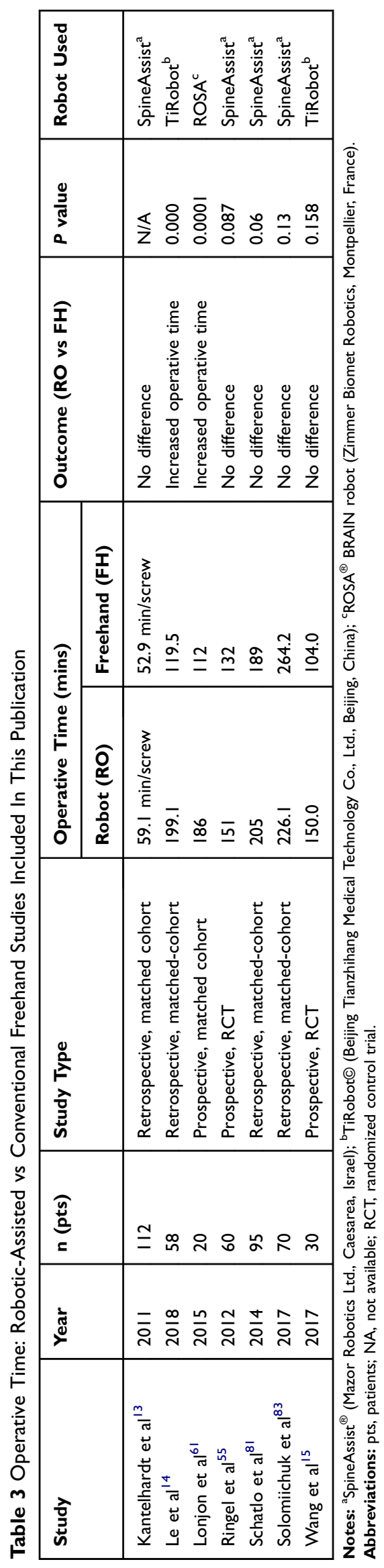

\section{Cost-Benefit Analysis}

Between 2001 and 2010, roughly 3.6 million spinal fusions were performed, with a total estimated cumulative cost of these procedures exceeding $\$ 287$ billion. ${ }^{89}$ With over $40 \%$ of adults aged 40 years and older suffering from spinal disease, current initiatives should focus not only on improving operative outcomes but also on lowering costs. Potential economic savings gained by using robots in spine surgery can be estimated by considering the decreased operative time, patient length of stay, fluoroscopic exposure, and surgical revision rates that robots may increasingly provide in the future. ${ }^{56,90}$ Accounting for these changes, the worldwide market for robots in spinal surgery is expected to increase from $\$ 26$ million to $\$ 2.77$ billion by $2022{ }^{1}$

A robust multi-center prospective study, entitled MIS ReFRESH, is currently underway with goals of measuring differences in surgical complication rates, rate of revision surgeries, and exposure to intraoperative radiation with different screw placement techniques in various adult degenerative diseases. ${ }^{91}$ Preliminary reports from this study demonstrate a $75 \%$ reduction in fluoroscopy needed for pedicle screw insertion within the robotic group (RO) compared to the freehand group (FH) $(3.2 \mathrm{~s} / \mathrm{screw}[\mathrm{RO}] \mathrm{vs}$ $12.5 \mathrm{~s} /$ screw $[\mathrm{FH}] ; \mathrm{P}<0.001)$. There were significantly less complications and revisions in the robotic arm $(\mathrm{P}=0.03)$; however, this result is limited by the small sample size and limited follow-up period. ${ }^{91}$ Decreases in rates of revision spine surgery may ultimately be the most effective means of cost savings in this patient population due to both the increased direct costs of additional surgery and the indirect cost of prolonged patient disability. ${ }^{56}$

Another study found a $46 \%$ reduction in revision surgeries when using the SpineAssist. ${ }^{13}$ In this study, Kantelhardt et al also demonstrated that patients in the robotic arm spent significantly fewer days in the hospital (10.6 days $[\mathrm{RO}]$ vs 14.6 days $[\mathrm{FH}] ; \mathrm{P}=0.009$ ). It is also interesting to note that, of the patients not taking opioids pre-operatively, significantly fewer patients undergoing robotic screw placement required new postoperative opioids compared to those undergoing conventional screw placement $(45.5 \%$ [RO] vs $88.9 \%$ [FH]; $\mathrm{p}=0.0002) .{ }^{13}$

Menger et al conducted a large, retrospective study of 557 patients and found robotic surgery to be cost-effective, resulting in reduced length of stay, fewer revision surgeries, lower infection rates, and shorter operative time. ${ }^{92}$ Of the 557 patients, $10 \%$ underwent MIS fusions, and 
another $10 \%$ would have been candidates as determined by an independent reviewer. More interestingly, they detailed how improved screw accuracy in robotic surgery would allow for the conversion of more cases to MIS. MIS has been shown to result in reduced length of stay and fewer post-operative infections. Further, with the demonstrated $4.6 \%$ infection rate for open surgery and $0.0 \%$ infection rate for MIS, robotic technology could save $\$ 36,312$ from reduced infections alone. They also found that MIS robotic procedures saved 3.4 mins per spinal level involved, resulting in annual savings of $\$ 5,713 .^{92}$ The improved accuracy resulted in 9.47 avoided revisions and savings of $\$ 314,661$. Total savings secondary to robotic technology at this one academic center amounted to $\$ 608,546$ in the one-year period. ${ }^{92}$

In terms of associated costs, the SpineAssist and Renaissance are the most utilized robots worldwide, and hence, the most studied in the literature. ${ }^{1,39,59}$ While the Renaissance cost close to $\$ 1,000,000$ a few years ago, the launch of the new Mazor X caused its price to drop to $\$ 550,000$, inclusive of all hardware and installation but exclusive of implants and disposables. ${ }^{56,93-95}$ Since hospitals charge between $\$ 40,000$ and $\$ 80,000$ for a lumbar spine fusion, between ten and twelve lumbar surgeries are needed to pay back initial costs. ${ }^{94}$ Maintenance and annual service expenses cost the center an additional 10\% of the list price annually.

Even with these high initial and maintenance costs, robotic surgery can become cost-effective in the long run if fewer revisions, lower infection rates, reduced length of stay, and shorter operative times are achieved. ${ }^{91,92}$ Overall, there is a massive shortage of studies specifically analyzing the cost-effectiveness of robots in spine surgery, necessitating future work on the topic.

\section{Future Advances}

With its ever-expanding indications and improvements, robotic technology in spine surgery holds immense promise. More and more, robots have been increasingly utilized for spinal tumor resections, radiofrequency ablations, and osteotomies in deformity surgeries in addition to other brain procedures. ${ }^{56}$ Further, manufacturers are actively working on creating lighter, more portable and more affordable robots in order to increase their accessibility and usability. Cambridge Medical Robotics ${ }^{\mathrm{TM}}$, for example, plans to introduce comprehensive packages which would include robotic system maintenance, instruments, and surgical assistants all for one flat price. These packages will help reduce costs and labor for hospitals, patients, and scientists alike. ${ }^{96}$

Also likely on its way in the next era of robotics is the incorporation of the Internet of Skills and Artificial Intelligence (AI). The Internet of Skills utilizes ultra-fast, low-latency $5 \mathrm{G}$ connectivity in order to allow a surgeon the ability to operate remotely, with delays of less than $10 \mathrm{~ms}$ for distances up to $1500 \mathrm{~km}$. To further reduce this delay, however, robots may be trained using AI and machine learning so that they may predict surgical movements, thereby allowing the surgeon to operate from even longer distances with an even shorter delay. This technology may also expand to surgical training programs as trainees can learn from surgical operations uploaded to the Internet as if they were in the operating rooms themselves. ${ }^{97}$ Along these lines, many virtual reality (VR) and augmented reality (AR) systems have already been incorporated into surgical training programs, and some of these simulation platforms have been correlated with improvements in trainees' operative time and overall performance. $^{98,99}$

Incorporating the use of VR and AR in neurosurgery, Madhavan et al described their vision for the next generation of a semi-independent spine robot. ${ }^{100}$ They envisioned this bed-mounted/attached robot to possess two or more arms, each equipped with two to three joints and all the necessary tools to place a percutaneous screw and rod system. The surgeon could supervise the operation either directly or through an AR headset, controlling the robot with voice commands or another control system. The AR headset could display 3D visualizations of screw trajectories and pre- and intraoperative imaging scans individually. By merging these two, the headset could even project target structures onto the patient. ${ }^{100}$ Displays equipped with the ability to overlay images onto the surgical field have previously been found to enhance the surgeons' operating experience. ${ }^{101}$ Further, sensor gloves could ensure natural hand motions and greater haptic feedback. ${ }^{100}$

In Japan, Ueda et al developed a robotic simulator with the ability to provide autonomous collision avoidance to the surgeon. ${ }^{18}$ This concept of autonomous collision avoidance is especially useful in spinal operations as neurosurgeons and orthopedists often must use thin and long instruments for dissection. Another robot that has been developed and is nearing clearance for human testing is the Smart Tissue Autonomous Robot (STAR). This robot has demonstrated the ability to autonomously perform certain surgical procedures on pigs, like suturing tissue. ${ }^{102,103}$ 


\section{Conclusion}

Initial clinical studies regarding robotic-assisted spinal surgery suggest that it may be more accurate, more efficient, and safer for pedicle screw instrumentation and other spinal procedures compared to traditional fluoroscopic-assisted freehand approaches. However, further clinical evaluation is required to increase the statistical power of these conclusions and define its future applications, limitations, and areas of improvement. ${ }^{6}$ Further, even though one of the main issues limiting the widespread adoption of robots in spinal surgery worldwide is its associated costs, there still remains a lack of studies on the cost-effectiveness of these procedures. $^{33,56}$ Nevertheless, with newer technology, future generations of robots have immense potential to improve spine surgery for both patients and providers alike.

\section{Disclosure}

The authors report no conflicts of interest in this work.

\section{References}

1. OpenPR. Global Surgical Robots for the Spine Industry Trend, Growth, Shares, Strategy and Forecasts 2016 to 2022; 2017. Available from: https://www.openpr.com/news/442943/global-surgi cal-robots-for-the-spine-industry-trend-growth-shares-strategy-andforecasts-2016-to-2022.html. Accessed October 25, 2019.

2. Yu L, Chen X, Margalit A, Peng H, Qiu G, Qian W. Robot-assisted vs freehand pedicle screw fixation in spine surgery - a systematic review and a meta-analysis of comparative studies. Int J Med Robot Comput Assist Surg. 2018;14:e1892. doi:10.1002/rcs.1892

3. Devito DP, Kaplan L, Dietl R, et al. Clinical acceptance and accuracy assessment of spinal implants guided with spineassist surgical robot: retrospective study. Spine (Phila Pa 1976). 2010;35:2109-2115. doi:10.1016/j.jaridenv.2015.11.005

4. Shoham M, Lieberman IH, Benzel EC, et al. Robotic assisted spinal surgery-from concept to clinical practice. Comput Aided Surg. 2007;12(2):105-115. doi:10.3109/10929080701243981

5. Cahill KS, Wang MY. Evaluating the accuracy of robotic assistance in spine surgery. Neurosurgery. 2012;71:N20-N21. doi:10.1227/01. neu.0000417535.07871.36

6. Hu X, Ohnmeiss DD, Lieberman IH. Robotic-assisted pedicle screw placement: lessons learned from the first 102 patients. Eur Spine J. 2013;22:661-666. doi:10.1007/s00586-012-2499-1

7. Podolsky DJ, Martin AR, Whyne CM, Massicotte EM, Hardisty MR, Ginsberg HJ. Exploring the role of 3-dimensional simulation in surgical training: feedback from a pilot study. $J$ Spinal Disord Tech. 2010;23:e70-e74. doi:10.1097/BSD.0b013e3181d34 $5 \mathrm{cb}$

8. Jutte PC, Castelein RM. Complications of pedicle screws in lumbar and lumbosacral fusions in 105 consecutive primary operations. Eur Spine J. 2002;11:594-598. doi:10.1007/s00586-0020469-8

9. Kosmopoulos V, Schizas C. Pedicle screw placement accuracy: A meta-analysis. Spine (Phila Pa 1976). 2007;32:E111-E120. doi:10.1097/01.brs.0000254048.79024.8b
10. Kotani Y, Abumi K, Ito M, Minami A. Improved accuracy of computer-assisted cervical pedicle screw insertion. J Neurosurg Spine. 2003;99:257-263. doi:10.3171/spi.2003.99.3.0257

11. Rajasekaran S, Vidyadhara S, Ramesh P, Shetty AP. Randomized clinical study to compare the accuracy of navigated and nonnavigated thoracic pedicle screws in deformity correction surgeries. Spine (Phila Pa 1976). 2007;32:E56-E64. doi:10.1097/ 01.brs.0000252094.64857.ab

12. Tian N-F, Huang Q-S, Zhou P, et al. Pedicle screw insertion accuracy with different assisted methods: A systematic review and meta-analysis of comparative studies. Eur Spine J. 2011;20:846-859. doi:10.1007/s00586-010-1577-5

13. Kantelhardt SR, Martinez R, Baerwinkel S, Burger R, Giese A, Rohde V. Perioperative course and accuracy of screw positioning in conventional, open robotic-guided and percutaneous roboticguided, pedicle screw placement. Eur Spine J. 2011;20:860-868. doi:10.1007/s00586-011-1729-2

14. Le X, Tian W, Shi Z, et al. Robot-assisted versus fluoroscopyassisted cortical bone trajectory screw instrumentation in lumbar spinal surgery: a matched-cohort comparison. World Neurosurg. 2018;120:e745-e751. doi:10.1016/j.wneu.2018.08.157

15. Wang JQ, Wang Y, Feng Y, et al. Percutaneous sacroiliac screw placement: A prospective randomized comparison of robotassisted navigation procedures with a conventional technique. Chin Med J (Engl). 2017. doi:10.4103/0366-6999.217080

16. Roser F, Tatagiba M, Maier G. Spinal robotics: current applications and future perspectives. Neurosurgery. 2013;72:A12-A18. doi:10.1227/NEU.0b013e318270d02c

17. Lanfranco AR, Castellanos AE, Desai JP, Meyers WC. Robotic Surgery: A Current Perspective. Ann Surg. 2004;239:14-21. doi:10.1097/01.sla.0000103020.19595.7d

18. Ueda H, Suzuki R, Nakazawa A, et al. Toward autonomous collision avoidance for robotic neurosurgery in deep and narrow spaces in the brain. Procedia CIRP. 2017;65:110-114. doi:10.1016/j.procir.2017.04.027

19. Chenin L, Peltier J, Lefranc M. Minimally invasive transforaminal lumbar interbody fusion with the ROSATM Spine robot and intraoperative flat-panel CT guidance. Acta Neurochir (Wien). 2016;158:1125-1128. doi:10.1007/s00701-016-2799-z

20. Kim VB, Chapman WHH, Albrecht RJ, et al. Early experience with telemanipulative robot-assisted laparoscopic cholecystectomy using da Vinci. Surg Laparosc Endosc Percutaneous Tech. 2002;12:33-40. doi:10.1097/00019509-200202000-00006

21. Fuchs K. Minimally Invasive Surgery. Endoscopy. 2002;34:154159. doi:10.1055/s-2002-19857

22. Allendorf JDF, Bessler M, Whelan RL, et al. Postoperative immune function varies inversely with the degree of surgical trauma in a murine model. Surg Endosc. 1997. doi:10.1007/ s004649900383

23. Lee JC, Jang HD, Shin BJ. Learning curve and clinical outcomes of minimally invasive transforaminal lumbar interbody fusion: our experience in 86 consecutive cases. Spine (Phila Pa 1976). 2012;37:1548-1557. doi:10.1097/BRS.0b013e318252d44b

24. Kwoh YS, Hou J, Jonckheere EA, Hayati S. A robot with improved absolute positioning accuracy for CT guided stereotactic brain surgery. IEEE Trans Biomed Eng. 1988;35:153-160. doi: $10.1109 / 10.1354$

25. Davies B. A review of robotics in surgery. Proc Inst Mech Eng Part H J Eng Med. 2000;214:129-140. doi:10.1243/0954411001535309

26. Singh J, Podolsky ER, Castellanos AE, Stein DE. Optimizing single port surgery: A case report and review of technique in colon resection. Int $J$ Med Robot Comput Assist Surg. 2011;7:127-130. doi:10.1002/rcs.378

27. Kaouk J, Valero R, Sawczyn G, Garisto J. Extra-peritoneal single port robotic radical prostatectomy: initial experience and description of technique. BJU Int. 2019. doi:10.1111/bju.14885 
28. Gomes MTV, Machado AMN, Podgaec S, Barison GAS. Initial experience with single-port robotic hysterectomy. Einstein (Sao Paulo). 2017;15:476-480. doi:10.1590/S1679-45082017AO4134

29. Dobbs RW, Halgrimson WR, Talamini S, Vigneswaran HT, Wilson JO, Crivellaro S. Single-port robotic surgery: the next generation of minimally invasive urology. World J Urol. 2019; (0123456789). doi:10.1007/s00345-019-02898-1

30. Grochola LF, Soll C, Zehnder A, Wyss R, Herzog P, Breitenstein S. Robot-assisted versus laparoscopic single-incision cholecystectomy: results of a randomized controlled trial. Surg Endosc. 2019;33(5):1482-1490. doi:10.1007/s00464-018-6430-7

31. Theodore N, Ahmed A, Karim B. The History of Robotics in Spine Surgery. Spine (Phila Pa 1976). 2018;43(7):23. doi:10.1097/BRS.0000000000002553

32. Dogangil G, Davies BL, Rodriguez Y, Baena F. A review of medical robotics for minimally invasive soft tissue surgery. Proc Inst Mech Eng Part H J Eng Med. 2010;224:653-679. doi:10.1243/09544119JEIM591

33. Shweikeh F, Amadio JP, Arnell M, et al. Robotics and the spine: a review of current and ongoing applications. Neurosurg Focus. 2014;36:E10. doi:10.3171/2014.1.FOCUS13526

34. Barzilay Y, Liebergall M, Fridlander A, Knoller N. Miniature robotic guidance for spine surgery - introduction of a novel system and analysis of challenges encountered during the clinical development phase at two spine centres. Int J Med Robot Comput Assist Surg. 2006;2(2):146-153. doi:10.1002/rcs.90

35. Sukovich W, Brink-Danan S, Hardenbrook M. Miniature robotic guidance for pedicle screw placement in posterior spinal fusion: early clinical experience with the SpineAssist? Int J Med Robot Comput Assist Surg. 2006;2:114-122. doi:10.1002/rcs.86

36. Schroerlucke SR, Wang MY, Cannestra AF, et al. Complication Rate in Robotic-Guided vs Fluoro-Guided Minimally Invasive Spinal Fusion Surgery: report from MIS Refresh Prospective Comparative Study. Spine J. 2017. doi:10.1016/j.spinee.2017.08.177

37. Business Wire. First Prospective Study of Robotic-Guided Spine Surgery Reveals Five-Fold Reduction in Surgical Complications with Mazor Core ${ }^{T M}$ Technology; 2017. Available from: https:// www.businesswire.com/news/home/20171025005354/en. Accessed October 25, 2019.

38. Hicks JM, Singla A, Shen FH, Arlet V. Complications of pedicle screw fixation in scoliosis surgery: A systematic review. Spine (Phila $\mathrm{Pa}$ 1976). 2010;35:E465-E470. doi:10.1097/BRS.0b013e3181d1021a

39. Overley SC, Cho SK, Mehta AI, Arnold PM. Navigation and robotics in spinal surgery: where are we now?. Clin Neurosurg. 2017;80:S86-S99. doi:10.1093/neuros/nyw077

40. Kazemi N, Crew L, Tredway T. The future of spine surgery: new horizons in the treatment of spinal disorders. Surg Neurol Int. 2013. doi:10.1074/jbc.M111.244400

41. Kim HJ, Kang KT, Park SC, et al. Biomechanical advantages of robot-assisted pedicle screw fixation in posterior lumbar interbody fusion compared with freehand technique in a prospective randomized controlled trial-perspective for patient-specific finite element analysis. Spine J. 2017. doi:10.1016/j.spinee.2016.11.010

42. Ravi B, Zahrai A, Rampersaud R. Clinical accuracy of computerassisted two-dimensional fluoroscopy for the percutaneous placement of lumbosacral pedicle screws. Spine (Phila Pa 1976). 2011;36(1):84-91. doi:10.1097/BRS.0b013e3181cbfd09

43. Mastrangelo G, Fedeli U, Fadda E, Giovanazzi A, Scoizzato L, Saia B. Increased cancer risk among surgeons in an orthopaedic hospital. Occup Med (Chic Ill). 2005;55:498-500. doi:10.1093/ occmed/kqi048

44. Hamilton DK, Smith JS, Sansur CA, et al. Rates of new neurological deficit associated with spine surgery based on 108,419 procedures: A report of the scoliosis research society morbidity and mortality committee. Spine (Phila Pa 1976). 2011;36:12181228. doi:10.1097/BRS.0b013e3181ec5fd9
45. Wang MY, Goto T, Tessitore E, Veeravagu A. Introduction. Robotics in neurosurgery. Neurosurg Focus. 2017;42(5):E1. doi:10.3171/2017.2.FOCUS1783

46. Faria C, Erlhagen W, Rito M, De Momi E, Ferrigno G, Bicho E. Review of robotic technology for stereotactic neurosurgery. IEEE Rev Biomed Eng. 2015;8:125-137. doi:10.1109/RBME.2015. 2428305

47. Vardy E, Robinson JE, Li C, et al. A new DREADD facilitates the multiplexed chemogenetic interrogation of behavior. Neuron. 2015;86(4):936-946. doi:10.1016/j.neuron.2015.03.065

48. Bertelsen A, Melo J, Sánchez E, Borro D. A review of surgical robots for spinal interventions. Int $J$ Med Robot Comput Assist Surg. 2013;9:407-422. doi:10.1002/rcs.1469

49. Shoham M, Burman M, Zehavi E, Joskowicz L, Batkilin E, Kunicher Y. Bone-mounted miniature robot for surgical procedures: concept and clinical applications. IEEE Trans Robot Autom. 2003;19:893-901. doi:10.1109/TRA.2003.817075

50. Tjardes T, Shafizadeh S, Rixen D, et al. Image-guided spine surgery: state of the art and future directions. Eur Spine J. 2010;19:25-45. doi:10.1007/s00586-009-1091-9

51. Nathoo N, Çavuşoğlu MC, Vogelbaum MA, Barnett GH. In touch with robotics: neurosurgery for the future. Neurosurgery. 2005;56:421-433. doi:10.1227/01.NEU.0000153929.68024.CF

52. Dreval ON, Rynkov IP, Kasparova KA, Bruskin A, Aleksandrovskii $\mathrm{V}$, Bernstein VZIL. Results of using spine assist mazor in surgical treatment of spine disorders. Zhurnal Vopr Neirokhirugii Im $N$ N Burdenko. 2014.

53. Lieberman IH, Togawa D, Kayanja MM, et al. Bone-mounted miniature robotic guidance for pedicle screw and translaminar facet screw placement: part I - Technical development and a test case result. Neurosurgery. 2006;59:641-650. doi:10.1227/01. NEU.0000229055.00829.5B

54. Togawa D, Kayanja MM, Reinhardt MK, et al. Bone-mounted miniature robotic guidance for pedicle screw and translaminar facet screw placement: part 2 - Evaluation of system accuracy. Neurosurgery. 2007. doi:10.1227/01.NEU.0000249257.16912.AA

55. Ringel F, Stüer C, Reinke A, et al. Accuracy of robot-assisted placement of lumbar and sacral pedicle screws: A prospective randomized comparison to conventional freehand screw implantation. Spine (Phila Pa 1976). 2012;37:E496-E501. doi:10.1097/ BRS.0b013e31824b7767

56. Fiani B, Quadri SA, Farooqui M, et al. Impact of robot-assisted spine surgery on health care quality and neurosurgical economics: a systemic review. Neurosurg Rev. 2018. doi:10.1007/s10143018-0971-z

57. Suliman A, Wollstein R, Bernfeld B, Bruskin A. Robotic-assisted device in posterior spinal fusion for a high risk thoraculombar fracture in ankylosing spondylitis. Asian Spine J. 2014;8:64. doi:10.4184/asj.2014.8.1.64

58. Kim H-J, Lee SH, Chang B-S, et al. Monitoring the quality of robot-assisted pedicle screw fixation in the lumbar spine by using a cumulative summation test. Spine (Phila Pa 1976). 2015;40:8794. doi:10.1097/BRS.0000000000000680

59. Joseph JR, Smith BW, Liu X, Park P. Current applications of robotics in spine surgery: a systematic review of the literature. Neurosurg Focus. 2017;42:E2. doi:10.3171/2017.2.FOCUS16544

60. Khan A, Meyers JE, Siasios I, Pollina J. Next-generation robotic spine surgery: first report on feasibility, safety, and learning curve. Oper Neurosurg. 2018. doi:10.1093/ons/opy280

61. Lonjon N, Chan-Seng E, Costalat V, Bonnafoux B, Vassal M, Boetto J. Robot-assisted spine surgery: feasibility study through a prospective case-matched analysis. Eur Spine J. 2016;25:947955. doi:10.1007/s00586-015-3758-8

62. Lefranc M, Peltier J. Evaluation of the ROSA ${ }^{\mathrm{TM}}$ Spine robot for minimally invasive surgical procedures. Expert Rev Med Devices. 2016;13:899-906. doi:10.1080/17434440.2016.1236680 
63. Nuzzi R, Brusasco L. State of the art of robotic surgery related to vision: brain and eye applications of newly available devices. Eye Brain. 2018; Volume 10:13-24. doi:10.2147/EB.S148644

64. Intuitive Surgical Inc. da Vinci Si System with single-site instrumentation. Available from: https://www.intuitivesurgical.com/company/ media/images/singlesite.php. Accessed September 30, 2019.

65. Beutler WJ, Peppelman WC, Dimarco LA. The da vinci robotic surgical assisted anterior lumbar interbody fusion: technical development and case report. Spine (Phila Pa 1976). 2013;38:356-363. doi:10.1097/BRS.0b013e31826b3d72

66. Moskowitz RM, Young JL, Box GN, Paré LS, Clayman RV. Retroperitoneal transdiaphragmatic robotic-assisted laparoscopic resection of a left thoracolumbar neurofibroma. JSLS. 2009;13 (1):64-68.

67. Yang MS, Yoon DH, Kim KN, et al. Robot-assisted anterior lumbar interbody fusion in a swine model in vivo test of the da vinci surgicalassisted spinal surgery system. Spine (Phila Pa 1976). 2011;36:E139E143. doi:10.1097/BRS.0b013e3181d40ba3

68. Satava RM. Surgical robotics: the early chronicles: A personal historical perspective. Surg Laparosc Endosc Percutaneous Tech. 2002. doi:10.1097/00019509-200202000-00002

69. Lee JYK, Bhowmick DA, Eun DD, Welch WC. Minimally invasive, robot-assisted, anterior lumbar interbody fusion: A technical note. J Neurol Surg Part A Cent Eur Neurosurg. 2013;74:258261. doi:10.1055/s-0032-1330121

70. Perez-Cruet MJ, Welsh RJ, Hussain NS, Begun EM, Lin J, Park P. Use of the da Vinci minimally invasive robotic system for resection of a complicated paraspinal schwannoma with thoracic extension: case report. Neurosurgery. 2012. doi:10.1227/ NEU.0b013e31826112d8

71. Inamasu J, Guiot BH. Laparoscopic anterior lumbar interbody fusion: A review of outcome studies. Minim Invasive Neurosurg. 2005;48:340-347. doi:10.1055/s-2005-915634

72. Liu JC, Ondra SL, Angelos P, Ganju A, Landers ML. Is laparoscopic anterior lumbar interbody fusion a useful minimally invasive procedure? Neurosurgery. 2002. doi:10.1227/01. NEU.0000031067.30674.7C

73. Chung SK, Lee SH, Lim SR, et al. Comparative study of laparoscopic L5-S1 fusion versus open mini-ALIF, with a minimum 2year follow-up. Eur Spine J. 2003;12:613-617. doi:10.1007/ s00586-003-0526-y

74. Kaiser MG, Haid RW, Subach BR, et al. Comparison of the miniopen versus laparoscopic approach for anterior lumbar interbody fusion: A retrospective review. Neurosurgery. 2002;51:97-105. doi:10.1097/00006123-200207000-00015

75. Zygourakis CC, Ahmed AK, Kalb S, et al. Technique: open lumbar decompression and fusion with the Excelsius GPS robot. Neurosurg Focus. 2018;45:V6. doi:10.3171/2018.7.FocusVid.18123

76. $\mathrm{Hu} \mathrm{X}$, Lieberman IH. What is the learning curve for roboticassisted pedicle screw placement in spine surgery? Clin Orthop Relat Res. 2014;472:1839-1844. doi:10.1007/s11999013-3291-1

77. Bai Y-S, Zhang Y, Chen Z-Q, et al. Learning curve of computerassisted navigation system in spine surgery. Chin Med J (Engl). 2010;123(21):2989-2994.

78. Kim HJ, Jung WI, Chang BS, Lee CK, Kang KT, Yeom JS. A prospective, randomized, controlled trial of robot-assisted vs freehand pedicle screw fixation in spine surgery. Int $\mathrm{J} \mathrm{Med}$ Robot Comput Assist Surg. 2017;13:e1779. doi:10.1002/ rcs. 1779

79. Kaul S, Shah NL, Menon M. Learning curve using robotic surgery. Curr Urol Rep. 2006;7:125-129. doi:10.1007/s11934-0060071-4

80. Keric N, Doenitz C, Haj A, et al. Evaluation of robot-guided minimally invasive implantation of 2067 pedicle screws. Neurosurg Focus. 2017;42:E11. doi:10.3171/2017.2.FOCUS16552
81. Schatlo B, Molliqaj G, Cuvinciuc V, Kotowski M, Schaller K, Tessitore E. Safety and accuracy of robot-assisted versus fluoroscopy-guided pedicle screw insertion for degenerative diseases of the lumbar spine: a matched cohort comparison. $J$ Neurosurg Spine. 2014;20:636-643. doi:10.3171/2014.3.SPINE 13714

82. Gras F, Marintschev I, Wilharm A, Klos K, Mückley T, Hofmann GO. 2D-fluoroscopic navigated percutaneous screw fixation of pelvic ring injuries - A case series. BMC Musculoskelet Disord. 2010;11. doi:10.1186/1471-2474-11-153

83. Solomiichuk V, Fleischhammer J, Molliqaj G, et al. Robotic versus fluoroscopy-guided pedicle screw insertion for metastatic spinal disease: a matched-cohort comparison. Neurosurg Focus. 2017;42:E13. doi:10.3171/2017.3.FOCUS1710

84. Kaoudi A, Capel C, Chenin L, Peltier J, Lefranc M. Robotassisted radiofrequency ablation of a sacral S1-S2 aggressive hemangioma. World Neurosurg. 2018;116:226-229. doi:10.1016/ j.wneu.2018.05.060

85. Bederman SS, Hahn P, Colin V, Kiester PD, Bhatia NN. Robotic Guidance for S2-Alar-Iliac Screws in Spinal Deformity Correction. Clin Spine Surg. 2017;30:E49-E53. doi:10.1097/ BSD.0b013e3182a3572b

86. Hu X, Lieberman IH. Robotic-guided sacro-pelvic fixation using S2 alar-iliac screws: feasibility and accuracy. Eur Spine J. 2017;26:720-725. doi:10.1007/s00586-016-4639-5

87. Hyun S-J, Kim K-J, Jahng T-A. S2 alar iliac screw placement under robotic guidance for adult spinal deformity patients: technical note. Eur Spine J. 2017;26:2198-2203. doi:10.1007/s00586017-5012-z

88. Laratta JL, Shillingford JN, Lombardi JM, et al. Accuracy of S2 alar-iliac screw placement under robotic guidance. Spine Deform. 2018;6:130-136. doi:10.1016/j.jspd.2017.08.009

89. Goz V, Weinreb JH, McCarthy I, Schwab F, Lafage V, Errico TJ. Perioperative complications and mortality after spinal fusions: analysis of trends and risk factors. Spine (Phila $\mathrm{Pa}$ 1976). 2013;38:1970-1976. doi:10.1097/BRS.0b013e3182a62527

90. Barzilay Y, Schroeder JE, Hiller N, et al. Robot-assisted vertebral body augmentation: A radiation reduction tool. Spine (Phila Pa 1976). 2014;39:153-157. doi:10.1097/BRS.000000 0000000100

91. Schroerlucke SR, Good CR, Wang MY. A prospective, comparative study of robotic-guidance versus freehand in minimally invasive spinal fusion surgery: first report from MIS ReFRESH. Spine J. 2016;16:S253. doi:10.1016/j.spinee.2016.07.166

92. Menger RP, Savardekar AR, Farokhi F, Sin A. A cost-effectiveness analysis of the integration of robotic spine technology in spine surgery. Neurospine. 2018;15(3):216-224. doi:10.14245/ ns. 1836082.041

93. Garrity M. Da Vinci Surgical System vs. Renaissance Robotic Surgical System - Is Mazor Robotics the Next Intuitive Surgical?; 2018. Available from: https://www.beckersspine.com/orthopedic-aspine-device-a-implant-news/item/39853-da-vinci-surgical-systemvs-renaissance-robotic-surgical-system-is-mazor-robotics-the-nextintuitive-surgical.html. Accessed October 25, 2019.

94. Young R. The March of Robots into the Spine Surgery Suite; 2012. Available from: https://ryortho.com/2012/09/the-march-ofrobots-into-the-spine-surgery-suite/. Accessed October 25, 2019.

95. Mazor Robotics, Ltd. Mazor X Stealth Edition Site PreInstallation Guide; 2018. Accessed October 25, 2019.

96. Aruni G, Amit G, Dasgupta P. New surgical robots on the horizon and the potential role of artificial intelligence. Investig Clin Urol. 2018;59(4):221-222. doi:10.4111/icu.2018.59.4.221

97. Kim SSY, Dohler M, Dasgupta P. The Internet of Skills: use of fifth-generation telecommunications, haptics and artificial intelligence in robotic surgery. BJU Int. 2018;122(3):356-358. doi:10.1111/bju. 14388 
98. Nagendran M, Gurusamy KS, Aggarwal R, Loizidou M, Davidson BR. Virtual reality training for surgical trainees in laparoscopic surgery. Cochrane Database Syst Rev. 2013. doi:10.1002/14651858.CD006575.pub3

99. Pelargos PE, Nagasawa DT, Lagman C, et al. Utilizing virtual and augmented reality for educational and clinical enhancements in neurosurgery. J Clin Neurosci. 2017;35:1-4. doi:10.1016/j.jocn.2016. 09.002

100. Madhavan K, Kolcun JPG, Chieng LO, Wang MY. Augmentedreality integrated robotics in neurosurgery: are we there yet? Neurosurg Focus. 2017;42(5):E3. doi:10.3171/2017.2.FOCUS177
101. Yoon JW, Chen RE, Kim EJ, et al. Augmented reality for the surgeon: systematic review. Int J Med Robot Comput Assist Surg. 2018;14(4):e1914. doi:10.1002/rcs.1914

102. Shademan A, Decker RS, Opfermann JD, Leonard S, Krieger A, Kim PCW. Supervised autonomous robotic soft tissue surgery. Sci Transl Med. 2016;8(337):337ra64. doi:10.1126/scitranslmed. aad 9398

103. Leonard S, Wu KL, Kim Y, Krieger A, Kim PCW. Smart tissue anastomosis robot (STAR): a vision-guided robotics system for laparoscopic suturing. IEEE Trans Biomed Eng. 2014;61 (4):1305-1317. doi:10.1109/TBME.2014.2302385

\section{Publish your work in this journal}

Robotic Surgery: Research and Reviews is an international, peer reviewed, open access, online journal publishing original research, commentaries, reports, and reviews on the theory, use and application of robotics in surgical interventions. Articles on the use of supervisorycontrolled robotic systems, telesurgical devices, and shared-control systems are invited. The manuscript management system is completely online and includes a very quick and fair peer review system, which is all easy to use. Visit http://www.dovepress.com/testimonials php to read real quotes from published authors. 